\title{
RECEPÇÃO, CIRCULAÇÃO E DISCIPLINARIZAÇÃO DA GESTALT- TERAPIA NO MATO GROSSO DO SUL
}

\author{
Reception, Circulation and Disciplinarization of Gestalt-therapy in Mato Grosso do Sul \\ Recepción, Circulación y Disciplinarización de la Gestalt-terapia en Mato Grosso do Sul
}

\author{
Lívia ElENa CunHa Laura \\ Ana Camila Marcelo \\ Elena dos SANTOS ARSAMENIA \\ GiovanNa Figueiredo BARZOTTO \\ Ana Maria Del Grossi FerReira Mota \\ RoDRIGo LOPES MirANDA
}

\begin{abstract}
Resumo: A Gestalt-terapia vem crescendo e se desenvolvendo desde de sua recepção na década de 1950. Para alguns autores, a Gestalt-terapia está envolvida no processo de recepção da fenomenologia na psicologia Humanista. Todavia, aspectos que envolvem o processo de formação de um conhecimento especializado e institucionalizado, como a disciplinarização dessa abordagem, são pouco visíveis no Mato Grosso do Sul (MS). Nesse cenário, esta pesquisa objetiva descrever e analisar formas de disciplinarização da Gestalt-terapia, em Mato Grosso do Sul, entre 1980 e 1990. Metodologicamente, esta é uma pesquisa em História da Psicologia que opera com Análise Documental e Análise de Conteúdo de fontes orais e textuais. Os resultados indicam que a disciplinarização da Gestalt-terapia ocorreu simultaneamente à graduação dos primeiros psicólogos, na cidade. Eles destacam, também, envolvimento nessa formação como uma possibilidade de expansão de conhecimentos, já que o cenário campo-grandense, à época, dificultava o acesso a formações complementares. Por fim, sinalizam um perfil de grupo eminentemente feminino e que salienta a importância de vivências terapêuticas no grupo de formação. Assim, ao desvelarmos esse processo, compreende-se determinados aspectos da história da Psicologia brasileira além de clarificar aspectos não narrados da história local, até então.
\end{abstract}

Palavras-chave: História da Psicologia; História Regional e Local; Psicologia Clínica; Gestalt-terapia.

\begin{abstract}
Gestalt Therapy has been growing and developing since its arrival in the 1950's. For some authors, Gestalttherapy is involved in the process of receiving phenomenology in Humanistic Psychology. However, specifics and institutionalized aspects of its studies, as disciplinarization, are barely visible in Mato Grosso do Sul (MS). In this scenario, this research aims to describe and analyze Gestalt-Therapy's disciplinarization in MS, between 1980 and 1990. Methodologically, this is a research in History of Psychology that uses Documentary and Content Analysis from oral and textual sources. Results indicate that Gestalt-Therapy's disciplinarization happened at the same time the firsts psychologists graduated in the city. They also highlight the involvement in the Gestalt-Therapy's training as a possibility of expansion knowledge, considering the scenario of Campo Grande, at the time, made it difficult to access complementary education. Finally, they suggest an eminently female group profile that shows the importance of therapeutic experiences in the group formation. Therefore, by unveiling this process, we understand certain aspects of the history of Brazilian Psychology, in addition to clarifying untold aspects of this local history.
\end{abstract}

Keywords: History of Psychology; Local History; Clinical Psychology; Gestalt Therapy.

Resumen: La Terapia gestáltica (GT), desde su recepción en la década de 1950, se ha desarrollado profusamente. Para algunos autores la terapia gestáltica está involucrada en el proceso de recepción de la fenomenología en la psicología humanística. Sin embargo, algunos aspectos disciplinares de ésta en Mato Grosso do Sul (MS) son poco visibles. En este escenario, esta investigación tiene como objetivo describir y analizar las formas de desarrollo disciplinar de la GT en MS, entre los años 1980 y 1990. Metodológicamente, este es un estudio en Historia de la Psicología que opera con análisis documental y de contenido de fuentes orales y textuales. Los resultados indican que el desarrollo disciplinar de la GT ocurrió junto con la graduación de los primeros psicólogos en la ciudad. Éstos destacan, que el interés en este enfoque terapéutico fue por la posibilidad de expansión de conocimientos, ya que el escenario campo-grandense de la época, dificultaba el acceso a formaciones complementarias. Finalmente, éstos señalan un perfil de grupo eminentemente femenino y que alentaba la importancia de vivencias terapéuticas en el grupo de formación. Es por ello que, al develar este proceso, se comprenden determinados aspectos de la historia de la psicología brasileña, además de clarificar aspectos hasta entonces no narrados de esa historia local.

Palabras clave: Historia de la Psicologia; Historia Regional y Local; Psicología Clínica; Gestalt Terapia. 


\section{Introdução}

A Psicologia brasileira passou por significativos incrementos entre as décadas de 1950 e 1970, no que diz respeito ao seu processo de institucionalização, disciplinarização e profissionalização. Alguns foram os marcos dessas décadas, tais como: a) a promulgação da Lei 4.119/62, a qual regulamentou a formação e a profissão de psicólogo; b) a criação do Sistema Conselhos; c) o crescimento do número de instituições que ofereciam cursos de graduação e pósgraduação; d) o aumento do número de Associações de Psicologia; e) o aumento do número de registros profissionais no Conselho Federal de Psicologia (CFP) e nos Conselhos Regionais (CRs), entre outros. Tais incrementos ocorreram concomitantemente a um conjunto de mudanças econômicas e socioculturais, particularmente associado à ascensão da classe média urbana, durante aquilo que foi chamado de “milagre econômico”, no Brasil. Nesse cenário, houve uma abertura ao consumo e ao estabelecimento do ideário de que a mudança social ocorreria por méritos individuais, o que, por sua vez, impactava a profissionalização da Psicologia como um campo clínico, em especial como um campo de atuação psicoterápico (Mancebo, 1999).

A relação desse cenário com o desenvolvimento da Psicologia Clínica, em um campo de atuação da psicoterapia, tem sido objeto de estudo no Brasil e alhures. Russo (2005), por exemplo, reflete que o "milagre econômico" fortaleceu discursos e práticas de investimentos na interioridade das pessoas e, também, sobre a importância do conhecimento de si. Batur (2011), investigando aspectos da Psicologia Clínica, na Turquia, salienta um processo similar de ascensão da classe média e da produção de um discurso de modernização urbana para a configuração de um campo psicoterápico no país. Esse tipo de estudo, portanto, sinaliza que a conformação de um certo cenário social, no mundo ocidental, esteve vinculada a uma valorização do indivíduo e, nessa seara, produziu-se certo discurso "psicologizante", i.e., levou-se ao reconhecimento de que as fragilidades e problemas eram, via de regra, problemas individuais e, não, psicossociais. Assim, tal desenvolvimento se relacionou com a produção de uma "sociedade psicologizada", a partir da interação entre o enfoque na individualização das práticas sociais, na ascensão da classe média urbana, em uma certa necessidade de gestão de pessoas e na expansão da Psicologia como ciência e profissão.

No Brasil, há indícios que, no cenário em questão, circulavam diferentes abordagens de Psicologia Clínica e de Psicoterapia, tais como Comportamentalistas, Humanistas e Psicanalíticas (Koch, 1975). No caso específico das abordagens chamadas Humanistas (cf. Holanda, 2014), isso ocorria, especialmente, por influência de psicólogos que estudaram nos Estados Unidos da América (EUA), país que, à época, assistia ao desenvolvimento das ideias e práticas associadas a Carl Rogers [desenvolveu abordagem centrada na pessoa], Friederich Perls [desenvolveu Gestaltterapia] e Viktor Frankl [desenvolveu a logoterapia] (Gomes, Holanda \& Gauer, 2004). No país, os psicólogos brasileiros criavam, ainda, condições para que, além da leitura e do contato com tais autores de fora do país, os recepcionassem aqui (Castelo Branco, Farias \& Leite, 2017). Destarte, muitas abordagens consideradas humanistas passaram a se desenvolver no país, dentre elas a Gestalt-terapia. Para Spiegelberg (1972) a Gestaltterapia pode ser considerada uma representante do movimento fenomenológico na Psicologia. Outras investigações, desvelam, ainda, produções atuais que contemplam uma base fenomenológica da Gestalt-terapia (Müller-Granzotto \& MüllerGranzotto, 2007). Segundo Moreira (2009), nessas produções teóricas atuais a "ênfase fenomenológica por meio do diálogo com vários pensadores fenomenológicos e existenciais potencializa novos caminhos para uma compreensão fenomenológica e existencial dos conceitos da Gestalt-terapia, originalmente formulados por Frederick Perls" (p. 7). Nessa direção, dentre as diferentes abordagens de Psicologia clínica, que circularam, à época, no país, havia algumas abordagens de influências fenomenológicas e existenciais, entendidas como humanistas, dentre elas a Gestalt-terapia (CasteloBranco \& Cirino, 2017; Castelo-Branco \& Carpes, 217; Gomes, et, al., 2004).

No que se refere especificamente à Gestaltterapia, no Brasil, há indícios de que seus estudos e aplicações vêm crescendo e se desenvolvendo, desde sua recepção, na década de 1950 (Castelo-Branco \& Farias, 2020; Holanda, 2009; Holanda \& Karwowski, 2004). Para esses autores, as regiões Sudeste e Centro-Oeste são, respectivamente, aquelas com maior número de produções de dissertações e teses, na abordagem. Inclusive, porque em tais regiões houve uma concentração de figuras humanistas que recepcionaram os conhecimentos humanistas, tais como o Jorge Ponciano (Castelo Branco \& Farias, 2020; Castelo Branco \& Carpes, 2017). Inclusive, Jorge Ponciano, teria tido o papel de ser um dos facilitadores da expansão e circulação da abordagem em diversos estados do Brasil, entre eles o atual Mato Grosso do Sul (Suassuna \& Holanda, 2008). No entanto, ao nos debruçarmos na região Centro-Oeste, os números se restringem às cidades de Brasília e Goiás, exclusivamente. Dessa forma, dados sobre sua circulação e produção em outros espaços, tais como o Mato Grosso do Sul (MS), são pouco visíveis.

Diante do exposto, objetivamos descrever e analisar formas de recepção e circulação da Gestaltterapia, em MS, entre 1980 e 1990. Particularmente, focalizamos em aspectos da sua disciplinarização, a partir da formação da primeira turma que se "especializou” em Gestalt-terapia, na capital do 
estado, Campo Grande, entre 1985 e 1987. Para tanto, entendemos o conceito de disciplinarização como um conjunto de pupilos e professores associados no entorno de um grupo de conhecimentos minimamente canonizados e vinculados a determinadas práticas (Gundlach, 2006). Logo, o envolvimento no processo de formação e a conclusão neste possibilita os pupilos à tornarem-se membros de um grupo específico, de Gestalt-terapeutas. Metodologicamente, esta pesquisa se caracteriza como uma História do Tempo Presente (Ferreira, 2000), inserida nos campos da História Social da Psicologia (Jansz, 2004/2009) e na História Crítica da Psicologia (Danziger, 1985). Utilizamos dois tipos de fontes, a saber: (1) textuais primárias e (2) orais, produto de entrevistas com seis pessoas que estiveram envolvidas com o referido curso. Assim, esta proposta dialoga com tendências atuais da História da Psicologia, quais sejam, compreender a relação global-local na história da Psicologia e como certos conhecimentos se tornaram locais. Nessa direção, compreender o processo de recepção e circulação da Gestalt-terapia, em MS, no período que compreende a formação da primeira turma de “especialistas” no campo, entre 1980 e 1990, contribui com a compreensão de determinados aspectos da história da Psicologia brasileira, além de clarificar aspectos ainda não narrados da história local.

\section{Contexto de Recepção: Modernização da Regiã̃o Oeste e Psicologia Clínica}

No início da década de 1960, o estado do Mato Grosso (MT) era composto por 84 municípios, caracterizando-se como um dos maiores estados do país, em quantidade de municípios, à época. Nesse período, articulações políticas em torno da divisão do estado foram engendradas, culminando no nascimento do estado de MS, em 1977. O estado nasceu já distribuído em 50 municípios, entre os quais se distribuíam em torno de um milhão de habitantes, em $350.549 \mathrm{~km}^{2}$ de extensão. O município eleito para capital do estado foi Campo Grande. Questões políticas, econômicas e sociais pareciam justificar o feito do então presidente, Ernesto Geisel, em desenvolver a região. Na mesma direção, Moro (2012) descreve:

(...) enquanto que o total da população brasileira cresceu em média 2,4\% de 1960-75, a população da Região Centro-Oeste cresceu 4,7\% no mesmo período. A população rural brasileira aumentou 0,6\% nessa época, sendo que a do Centro-Oeste cresceu 2,8\%. Já a população urbana do Brasil aumentou 4,4\%, sendo que a da Região Centro-Oeste cresceu a uma taxa de $7,3 \%$. (p.4)

Assim, notamos um cenário de expansão e investimento governamental na região Centro-
Oeste, particularmente no recém-surgido estado do Mato Grosso do Sul.

Nessa seara, vale lembrar que, entre 1964 e 1985, o Brasil vivia em uma ditadura civil-militar. Em meio às variadas preocupações do projeto modernizador do governo militar, duas merecem destaque no contexto desta pesquisa: a expansão para o Oeste e a universitária. No primeiro tópico, havia uma premência em intensificar a ocupação territorial brasileira para o Oeste, a partir de migrações de brasileiros e estrangeiros, como forma de ampliar a ocupação espacial e, consequentemente, influenciar no controle das fronteiras. De maneira geral, tal expansão tinha conotações políticas, econômicas e sociais: era um extenso território, com fronteiras internacionais - Paraguai e Bolívia - e de grande potencial para o desenvolvimento agropecuário. No que tange ao segundo item, o crescimento ocorreu vinculado à Reforma Universitária, que institucionalizava debates e preocupações que antecediam ao governo militar, e.g., a carência de recursos humanos para as empresas, o fato de as universidades não atenderem às demandas do mercado de trabalho, a necessidade de expansão do ensino superior para atender áreas prioritárias para o desenvolvimento do país, o planejamento de expansão de cursos de diferentes áreas e o desenvolvimento de tecnologias, entre outros objetivos (Motta, 2014). No caso específico da região ora ocupada por $\mathrm{MT} / \mathrm{MS}$, podemos conjecturar que se articulava a correlação entre o projeto de ocupação e o de formação superior. Investir nas migrações para a região poderia levar mão-de-obra qualificada de outras regiões e países, mas formar as pessoas que ali já viviam poderia fixar ainda mais indivíduos no Oeste brasileiro. Assim, formar mão-de-obra com ensino superior, na região de MT/MS, poderia manter a população em ritmo de crescimento, alvo do projeto expansionista da ditadura.

De forma geral, esse investimento na expansão universitária ocorreu, sobremaneira, pela criação de Instituições de Ensino Superior (IES) privadas. No final da década de 1960, o setor privado era responsável por 46\% das matrículas nas IES. Nessa direção, Sampaio (2000) afirma: "No período de 19601970, enquanto as matrículas públicas registravam crescimento da ordem de $260 \%$, as matrículas do setor privado cresciam mais de 500\%" (p. 57). O cenário do sul de MT, que se tornaria o estado de MS, exemplifica tal modelo de investimento: embora houvesse instituições públicas - como a Faculdade de Farmácia e Odontologia de Campo Grande, instalada em 1962, e o Instituto Superior de Pedagogia de Corumbá (ISPC), criado em 1967 -, foi o investimento privado, especificamente clerical, que marcou a região, à época. A Missão Salesiana de Mato Grosso (MSMT) criou a Faculdade Dom Aquino de Filosofia, Ciências e Letras ([FADAFI], 
1961), a Faculdade de Direito ([FADIR], 1966), a Faculdade de Ciências Econômicas, Contábeis e Administração ([FACECA], 1970) e a Faculdade de Serviço Social ([FASSO], 1972). Inclusive, a partir de 1975, com a integração dessas instituições, sob a denominação de Faculdades Unidas Católicas de Mato Grosso (FUCMT), iniciou-se o segundo curso de graduação em Psicologia, na região. O primeiro, instalado no ISPC, entre 1967 e 1968, ficava em Corumbá, uma região que se limitava a passar para o segundo plano, na dinâmica sociopolítica da região.

O cenário da constituição do ensino superior, na região, particularmente da Psicologia, aparece nas memórias do Entrevistado 6 (comunicação pessoal, 11 de dezembro de 2018): "Eu cheguei aqui em 1966, em 1967 nós criamos o curso de medicina e eu sentia falta de psicólogo" e ainda, "quando eu cheguei aqui, não tinha nem um psicólogo, tinha umas pedagogas que sabiam psicologia e davam aula de psicologia”. Esse entrevistado, cuja formação é médica, fornece indícios que havia uma preocupação com a constituição de um campo de atuação relacionado à saúde mental, na região. Ele nos diz: "Eu vim de Recife, eu trabalhava com equipe multiprofissional, trabalhava com psicólogo e trabalhava com assistente social e enfermeira, e eu acostumei a trabalhar em equipe, achava muito esquisito trabalhar sozinho". Essa demanda de profissionais em Psicologia coadunava, também, com certos horizontes sociais do sul de MT. A Entrevistada 2 (comunicação pessoal, 13 de dezembro de 2018) afirma, na mesma direção: "O momento era, assim, no que diz respeito a nossa situação, a situação específica da Psicologia em si, eu diria que era um momento de muita efervescência, porque ainda não existia cursos, né?" Logo, caminha-se na vertente do que pesquisas anteriores sugerem: havia uma demanda de escolarização superior por parte dos cidadãos da região, particularmente de Campo Grande, que ascendia no cenário político-econômico local (Mota, Cara \& Miranda, 2018). A demanda se manifestava, claramente, em direção à área da Psicologia, cujo vestibular, para as primeiras turmas da FUCMT, foi noticiado na mídia local e levou uma maioria feminina a "invadir a universidade" (Diário da Serra, 12 de janeiro de 1975).

Independentemente de quais aspectos o curso de graduação em Psicologia da FUCMT possa ter atendido, parece-nos que o processo de disciplinarização, que envolve a formação de pessoas vinculadas a um conjunto de conhecimento especializado e institucionalizado, foi marcado por um interesse pela área clínica. Alguns entrevistados sinalizaram a prática de estágios e acesso ao mercado de trabalho, após concluir o curso de graduação, na área da Psicologia Clínica. Vale ressaltar que todos aqueles que eram psicólogos se formaram no curso de graduação da FUCMT. A Entrevistada 6 (comunicação pessoal, 11 de dezembro de 2018), que havia estudado na FUCMT, diz: "As duplas de moças [no estágio] eram mais, para fazer observação clínica dos jovens, e perguntava sobre vida pessoal, vida profissional, vida sexual, da família, o trabalho". Em concordância, a Entrevistada 2 (comunicação pessoal, 07 de dezembro de 2018) sinaliza: "Eu trabalhei muitos anos, eu trabalhei mais de 15 anos no serviço de psiquiatria da Santa Casa". Esse tipo de atividade poderia estar ancorado naquele contexto ampliado, antes mencionado, de preocupação com o campo de atuação da Saúde Mental.

Assim, foi em um cenário de modernização da região do sul de MT, culminado na criação do estado de MS, em 1977, que os cursos de graduação em Psicologia se instalaram. De acordo com as fontes pesquisadas, esse cenário de modernização foi marcado por investimentos sociais no campo da Saúde Mental, particularmente da Psicologia e, mais especificamente, por um imaginário social da Psicologia Clínica. Isso ocorria, pari passu, a certo horizonte de modernização urbana de Campo Grande, alçada a capital do estado e reposicionada no cenário político-econômico do Centro-Oeste brasileiro. Nesse contexto é que surgiu, nas lembranças dos entrevistados, a apropriação das abordagens reconhecidas como Humanistas (Holanda, 2014) e, entre elas, a Gestalt-terapia.

\section{Características da Apropriacão: Psicologia Clínica e Formação em Gestalt-terapia}

O contexto de instalação dos cursos de graduação em Psicologia, do sul de MT, guarda uma particularidade que nos ajuda a entender certas lembranças dos entrevistados desta pesquisa. Tanto o curso do ISPC, criado em Corumbá entre 1967 e 1968, quanto aquele da FUCMT, em 1975, foram abertos como formação em Licenciatura Plena. Todavia, foi o segundo que se habilitou para a formação em Psicologia - um dos perfis de formação estimados legalmente, no Brasil, à época (ver Lei No. 4.119/62) -, primeiramente, em 1979. Dessa maneira, os primeiros formandos em Psicologia, da FUCMT, já poderiam ingressar em uma formação em Clínica, como, por exemplo, naqueles estágios que alguns de nossos entrevistados sinalizaram. Nesse cenário, a Entrevistada 3 (comunicação pessoal, 13 de dezembro de 2018) se recorda: "Eu me formei em 1981, na turma de 81, na então FUCMT, né? ... eu atendia em consultório e trabalhava também no serviço de psiquiatria onde eu atendia basicamente ambulatório de criança, né?!” Assim, aqueles psicólogos e psicólogas que se formavam, na FUCMT, poderiam ir, da maneira como nossa participante, para um campo de atuação em Psicologia Clínica.

Tal formação, no que tange a aspectos da Gestaltterapia, sinaliza certo horizonte de circulação de concepções humanistas. A Entrevistada 1 nos diz: "Não existia a Gestalt-terapia no curso, existia essa 
abordagem humanista e existencial, nem se falava muito em fenomenologia também" (comunicação pessoal, 06 de dezembro de 2018). Ela continua: "Marina [Ribeiro] foi a professora que trouxe a primeira informação da Gestalt-terapia para gente". Em 2015, o CRP da 14a região (CRP 14) homenageou Marina Ribeiro por seus feitos pela Psicologia no estado, bem como sua dedicação à docência lecionando na FUCMT por onze anos - e seu papel na institucionalização da Psicologia, na região. Cite-se, a título de exemplo, que ela fez parte da constituição do CRP 14 quando de sua desvinculação do CRP da $6^{\mathrm{a}}$ região (CRP 06), em 1996 e, ainda na década de 1990, foi uma das criadoras do Instituto de Gestalt-terapia do Mato Grosso do Sul (IGT). Nas lembranças dos entrevistados, no curso de Psicologia da FUCMT, não havia uma disciplina, ou prática clínica específica de Gestalt-terapia, logo sua circulação aconteceu entremeada nas abordagens humanistas. Essa característica, inclusive, vai ao encontro da literatura sobre a recepção e a circulação das abordagens conhecidas como Humanistas, no país. Os aportes da Fenomenologia e do Existencialismo parecem ser o denominador, frequentemente comum, que suscita a comunhão das distintas abordagens consideradas humanistas (Holanda, 2014). Ou seja, de forma singular, no Brasil, as abordagens humanistas abarcam algumas outras abordagens de influências fenomenológicas e existenciais, por exemplo, o Psicodrama (Castelo Branco et al., 2017; CasteloBranco \& Farias, 2020). Assim, segundo os autores, as abordagens humanistas, frequentemente, "são articuladas e pensadas em relação à Fenomenologia e ao Existencialismo, sendo vias para o aprendizado dessas filosofias e para o desenvolvimento de outras psicologias entendidas como fenomenológicas e existenciais" (Castelo-Branco et al., 2017, p. 3).

As fontes sugerem, ainda, que foi o contato com professores do curso de graduação, cujo discurso tinha similaridades com a Gestalt-terapia, que levou ao interesse das pessoas que, entre 1985 a 1987, participariam daquela que é conhecida como "primeira formação" do campo, no estado do MS. Nessa direção, por exemplo, a Entrevistada 4 (comunicação pessoal, 14 de dezembro de 2018) se recorda: "Me identifiquei muito com a Gestalt já desde a graduação". Entretanto, não foi apenas o interesse despertado pela circulação de temáticas próximas à Gestalt-terapia que levou aquelas pessoas ao curso. Outro elemento sinalizado pelas fontes foi a "oportunidade" de aprendizado. Nessa linha, a Entrevistada 2 (comunicação pessoal, 13 de dezembro de 2018) afirma:

No Serviço de Psiquiatria [de onde eu trabalhava], nós fizemos vários cursos em função mesmo da demanda tão complexa do serviço de psiquiatria, né? Então, a gente lá fez alguma coisa na base analítica com um ou outro professor, fizemos psicodrama, fizemos comportamental ... cognitiva, não cursos oficiais, cursos.... Mas cursos, abordagens que a gente estudava, às vezes fazia grupo de estudo, né? Justamente pra poder ter um know how maior de atendimento é... dos pacientes, né? Do serviço.

A interpretação de que poderiam ter elementos de "aproveitar a oportunidade" vai ao encontro de resultados de pesquisas sobre a história da Psicologia, em Campo Grande (Cara, 2017). Essa autora entrevistou ex-alunos do curso de graduação em Psicologia, da FUCMT e, nas falas de seus participantes, percebe-se um investimento dos acadêmicos em sua formação, considerando que havia dificuldades para que certas pessoas e objetos circulassem na cidade. Assim, uma de suas entrevistadas lembra de um "banco do livro", produzido pelos estudantes para que eles pudessem comprar poucos exemplares de obras que gostariam ou precisariam ler, mas que eram caras e não existiam na biblioteca. Além da questão do mercado editorial, à época, vale lembrar que Campo Grande estava afastada dos centros urbano-industriais do Sudeste. Dessa maneira, uma hipótese que podemos levantar é que, se era difícil ter acesso a materiais e profissionais novos, as oportunidades que apareciam deveriam ser "abraçadas", ainda mais se tais psicólogos e psicólogas se interessavam pela temática abordada.

Nesse cenário é que, entre março de 1985 e dezembro de 1987, aconteceu um curso de formação em Gestalt-terapia, em Campo Grande, totalizando 360 horas/aula. A certificação do curso era feita pelo Centro de Estudos de Gestalt-terapia de Brasília (CEGEST), com duas assinaturas: Jorge Ponciano Ribeiro (orientador) e Walter da Rosa Ribeiro (diretor). O nome de tais personagens e da cidade de Brasília condizem com outros estudos relacionados à história da Gestalt-terapia, no Brasil (Castelo Branco \& Farias, 2020). Essa literatura sinaliza que tal abordagem chegou ao Brasil na década de 1960 e sua apropriação se deu a partir da atuação de psicoterapeutas, nas cidades de Curitiba (Paraná [PR]) e Rio de Janeiro (Rio de Janeiro [RJ]) (Gomes et al., 2004). A partir dos anos 1970, ocorrera a circulação da abordagem para outras cidades e estados, como Brasília, que de acordo com Castelo Branco e Carpes (2017) foi relevante para o desenvolvimento da Gestalt-terapia brasileira: "A cidade, em 1977, incorporou o primeiro programa brasileiro de formação em Gestalt-terapia, regido por Walter Ribeiro" (p.82). Inclusive, as fontes relatam a oferta de cursos e programas de formação por Walter da Rosa Ribeiro, em 1977, na cidade de Brasília, como uma possibilidade de difícil acesso, à época (Entrevistada 5, comunicação pessoal, 21 de dezembro de 2018). Jorge Ponciano, por sua 
vez, começou sua carreira na Psicanálise, tendo estudado essa abordagem fora do país (Entrevistado 4, comunicação pessoal, 14 de dezembro de 2018). Os relatos sobre sua história sinalizam que sua aproximação à abordagem gestáltica ocorreu quando, de volta ao Brasil, em 1984, interessou-se por um curso que estaria sendo ofertado, em Brasília. Aparentemente, o curso em questão estava vinculado a Walter da Rosa Ribeiro. Esses dois personagens, em conjunto, teriam criado o Centro Especializado em Gestalt- Terapia (CEGEST), por volta de 1985 e 1987. Foi pelo CEGEST que o curso de formação em Gestalt-terapia foi ofertado, em Campo Grande. No entanto, anos mais tarde, tal parceria se desfez, culminando na oferta de cursos de formação em espaços diferentes, i.e., cada um em seu instituto.

Os participantes do curso de formação em Gestalt-terapia, de Campo Grande, eram recémformados ou finalizando a graduação em Psicologia, na sua maioria do curso de graduação da FUCMT, de forma que havia diferentes backgrounds: alguns realizavam estágio, enquanto outros já trabalhavam em clínicas. As fontes, quer sejam textuais ou orais, não indicam com exatidão o número de participantes do curso, mas sugerem algo entre 15 e 16 pessoas. Todavia, um ponto de convergência entre as memórias diz do sexo dos participantes: a predominância de mulheres. Nessa direção, por exemplo, a Entrevistada 5 (comunicação pessoal, 14 de dezembro de 2018) assevera: "E o Gilberto Verardo, né?! Que era homem né?! Porque a maioria, então, só tinha o Olavo [Bilac] e o Gilberto de homem, o resto era mulher".

A forte presença de mulheres no curso de formação coaduna com aquilo que ocorria na relação Psicologia e sexo feminino, em nível nacional e local. Censos e observações realizadas, desde a década de 1980, sinalizam que grande parte dos estudantes e formandos em Psicologia, no país, eram mulheres (Rosemberg, 1984). No caso específico de Campo Grande, essa correlação entre Psicologia e sexo feminino estava fortemente presente (Mota, Cara \& Miranda, 2018). Inclusive, como sinalizado anteriormente, a mídia local salientava de forma clara a demanda das mulheres da região pelo curso de graduação em Psicologia, da FUCMT (ver Diário da Serra, 12 de janeiro, 1975). Assim, se a maior parte dos participantes do curso de formação em Gestaltterapia vinham do curso de graduação em Psicologia da FUCMT e, nesse curso, houve predomínio feminino, estimaríamos que a maior probabilidade é de participantes mulheres. Vale ressaltar que, entre as décadas de 1960 e 1980, vemos a produção de uma "nova mulher" (Rutherford, 2012), caracterizada por uma crescente independência econômica e emocional, com liberdade de expressão em diferentes áreas de sua vida. Isso, no caso brasileiro, articulava-se com variadas transformações sociais para as mulheres, e.g., o estabelecimento da Lei do Divórcio, inserção no mercado de trabalho nas "carreiras modernas" (Sampaio, 2000), entre outras. Especificamente, em Campo Grande, parece que isso significou que um conjunto de mulheres procuravam o curso de graduação em Psicologia e, para qualificar sua prática, envolviam-se com uma formação posterior à graduação.

A proposta do curso era de, inicialmente, ser estruturado a partir de encontros mensais nos quais as despesas do professor orientador - Jorge Ponciano Ribeiro -, incluindo passagens e hospedagem, eram divididas entre os alunos participantes do curso (Entrevistada 5, comunicação pessoal, 14 de dezembro de 2018). Todavia, devido a dificuldades em manter financeiramente a vinda do professor, foi necessário repensar sua estrutura. Nas palavras da Entrevistada 1 (comunicação pessoal, 06 de dezembro de 2018): "A ideia era ser mensal, mas ninguém conseguiu pagar, aí virou bimestral e acabou sendo trimestral. Ele vinha no final de três em três meses". De acordo com a Entrevistada 5 (comunicação pessoal, 14 de dezembro de 2018), "Conseguimos a vinda para cá, para ofertar o curso, da pessoa mais qualificada, assim, ao nosso ver, na área de Gestalt-terapia, no país, foi o Jorge Ponciano”. A figura do professor aparece, de forma marcante, nas lembranças dos entrevistados, tais como as da Entrevistada 2 (comunicação pessoal, 21 de dezembro de 2018): "[Ribeiro] é um filósofo, né, então ele tinha uma bagagem de filosofia imensa que ele fazia a gente estudar muito a filosofia, né, o humanismo, o existencialismo, fenomenologia” e, ainda da Entrevistada 5 (comunicação pessoal, 21 de dezembro de 2018), a qual disse:

[Com isso] passamos a ampliar e compreender de onde vinha aquelas técnicas milagrosas, que elas não eram, sabe, uma receitinha de bolo, que aquilo ali tinha um fundamento enorme e foi aí que o Jorge [Ponciano Ribeiro], como um bom fenomenólogo, trouxe para gente, assim, né ... de forma muito consistente a fenomenologia.

Assim, as memórias sobre o Jorge Ponciano Ribeiro sinalizam-no como "a pessoa mais qualificada” que poderia assumir tal posição, porque "tinha uma bagagem de filosofia" e, com isso, trabalhava, com aquelas pessoas, uma abordagem "consistente" da Psicologia. Parece, ainda, que o adjetivo de "mais qualificada" está associada a uma bagagem filosófica, mais especificamente, atribuída aos aportes da fenomenologia e existencialismo. Assim, as lembranças dos participantes, sugerem uma base fenomenológica e existencial da Gestaltterapia, ensinada no curso. Fato esse, que dava o atributo qualificador de ser uma abordagem consistente.

Ainda sobre os encontros do curso de formação, que aconteciam na clínica de algumas alunas 
participantes do curso, como recorda a Entrevistada 4 (comunicação pessoal, 14 de dezembro de 2018):

A gente tinha um consultório que era muito interessante, clínica, que era uma casa grande com um subsolo, então na parte do térreo dela, no térreo eram todas as salas de atendimentos e descendo a escada a gente tinha um salão no subsolo, um salão grande ... uma sala, um salão com um piso muito interessante de madeira corrida com espelhos né?! Com espelhos em volta e fora dessa sala bem grande, era também uma área de lazer, verde. Então ali era nosso espaço de aula com as almofadas no chão. Então a gente se encontrava ali, ... a gente não tinha aulas formais, tradicionais, eram reuniões em grupos, nós em grupo, nas almofadas, estudando, discutindo, falando sobre.

Assim, havia um espaço adaptado para a realização do curso, no qual aquelas pessoas se encontravam, para sua formação em GestaltTerapia. Os entrevistados sinalizam que ocorriam aulas práticas e teóricas. As primeiras incluíam "nossa psicoterapia em grupo" (Entrevistada 5, comunicação pessoal, 14 de dezembro de 2018) e, as segundas, abordavam teoricamente aquilo que havia emergido das aulas práticas (Entrevistada 1, comunicação pessoal, 06 de dezembro de 2018). Em continuidade, a Entrevistada 2 (comunicação pessoal, 07 de dezembro de 2018) acrescenta: "Porque o grupo funcionava mais ou menos assim, as demandas aconteciam no grupo e ele [Jorge Ponciano] fazia as intervenções a partir dessas demandas e a teoria também vinha daí”. Além das aulas no consultório, também havia a programação em formato de workshop, que acontecia em algum local aberto: "A gente ia, por exemplo, para uma área da natureza mesmo, a gente ia pra uma chácara, onde tinha cachoeira e a gente passava ali, fazia um workshop num final de semana" (Entrevistada 5, comunicação pessoal, 14 de dezembro de 2018). Esse tipo de experiência nos ajudou a entender porque os participantes desse grupo de formação, como a própria Entrevistada 5, sinalizam que as técnicas psicoterápicas apresentadas por Jorge Ponciano Ribeiro eram "milagrosas". Elas poderiam ter adquirido tal qualificação pelo efeito que tiveram durante as aulas experienciais e workshops e, não necessariamente, pelo seu valor teórico.

As parcelas teóricas do curso se davam com a leitura de textos e das aulas práticas, por exemplo, o uso de conceitos teóricos-filosóficos para explicar/ ensinar ou ainda dar embasamento para técnicas e práticas. Sendo que a literatura circulava a partir do professor, Jorge Ponciano. Ou seja, ele disponibilizava materiais/textos e, a partir disso, os alunos organizavam grupos de estudos para se aprofundarem nas leituras por ele recomendadas
(Entrevistada 5, comunicação pessoal, 21 de dezembro de 2018). Na sequência, a Entrevistada 1 (comunicação pessoal, 07 de dezembro de 2018) sinaliza que:

(...) as referências bibliográficas que formaram a estrutura do curso de formação em Gestaltterapia foram dos autores [Siegmund Heinrich] Foulkes, [Friederich Salomon] Perls, [Charles Sanders] Peirce, [Joseph] Zinker, com artigos de [Martin] Heidegger, além da influência intelectual do próprio professor do curso, Jorge Ponciano [Ribeiro].

Mesmo não sendo possível analisar, de forma sistemática, as influências intelectuais que circularam entre os participantes do curso, pela lembrança dos participantes, a formação teórica ocorria pela leitura de diferentes autores, dentre eles expoentes da Gestalt-terapia, à época, por exemplo, Friederich Salomon Perls e Joseph Zinker e ainda, Martin Heidegger, filósofo do início do século XX. Todavia, pela lembrança dos participantes, a leitura ocorria a partir de fragmentos das obras: "Nós tínhamos fragmentos de livros, o livro dele [Jorge Ponciano Ribeiro] estava sendo escrito e outros artigos que a gente tinha que mandar traduzir para poder ler e estudar" (Entrevistada 1, comunicação pessoal, 07 de dezembro de 2018). Assim, a formação teórica ocorria, pelo esforço dos participantes, em terem acesso aos textos, e ainda assim, o acesso não era disponibilizado em um conjunto de materiais. Outrossim, o contato ocorria por materiais esparsos, excertos. Entretanto, vale salientar que tais memórias coadunam com os indicativos históricos sobre a produção e a tradução escrita em Gestalt-terapia, no país (Suassuna \& Holanda, 2008). As primeiras traduções publicadas de Perls ocorreram no final dos anos 1970, a saber: Isto é Gestalt (Perls, 1969/1977b) e Gestalt-terapia explicada (Perls,1975/1977a). Em meados da década de 1980 e 1990 começaram a circular, de forma mais sistemática, referenciais vinculados ao campo, como, por exemplo, os trabalhos Gestalt Therapy: Excitement and Growth in the Human Personality, de autoria de Fritz Perls, Ralph Hefferline e Paul Goodman (1951/1997) e Gestalt e Grupos, de Thérèse Tellegen (1984). Inclusive, a Entrevistada 1 (comunicação pessoal, 06 de dezembro de 2018) diz: "Gestalt-terapia chega através de Thérèse [Tellegen], ela que trouxe a Gestalt-terapia, foi o primeiro livro dela né, foi um artigo aí ela traduziu um livro e escreveu o dela em 1984”. Outro exemplo foi a publicação do livro de Jorge Ponciano Ribeiro, em 1985: Gestalt Terapia: Refazendo o caminho (Ribeiro, 1985). A fala dos entrevistados desta pesquisa sugere que a obra foi escrita concomitantemente ao curso realizado em Campo Grande: "No período em que ele escreveu o livro, ele ia trazendo os artigos, os capítulos para 
discutir com a gente" (Entrevistada 1, comunicação pessoal, 06 de dezembro de 2018).

Dessa maneira, a circulação de excertos de obras ou artigos parecia condizer com o zeitgeist do campo, à época, no Brasil: o início sistematizado de traduções para o português-brasileiro e com produções originais, feitas por brasileiros, em processo de escrita. Ademais, tal processo ocorria a partir da institucionalização das práticas de estudo e formação em Gestalt-terapia, no país. Por exemplo, vale lembrar que foi em 1976 que um grupo formado por Walter Ribeiro, Paulo Barros, Lílian Frazão e Abel Guedes passou a se reunir e produzir uma "formação" informal, no campo (Holanda \& Karwowski, 2004). Treinamentos formais ocorreriam a partir de 1977, como aquele outrora mencionado em Brasília. Apenas no início da década de 1980 se estabeleceram os primeiros núcleos de formação em Gestalt-terapia, no Brasil.

Entretanto, vale salientar que, apesar do interesse inicial pela Gestalt-terapia, poucos indivíduos desta primeira turma se mantiveram atuando na área, como dito pela Entrevistada 3 (comunicação pessoal, 13 de dezembro de 2018): "São poucas pessoas que se intitulam assim [GestaltTerapeutas], da minha época”. Nesta mesma direção a Entrevistada 5 (comunicação pessoal, 14 de dezembro de 2018) nos diz: "atualmente os cidadãos sul mato-grossenses que desejarem uma formação em Gestalt Terapia no estado, só podem contar com o Instituto Sul Matogrossense de Gestalt Terapia”. Esse quadro pode ser um dos motivos para, apesar da região Centro-Oeste apresentar grande circulação de artigos sobre a Gestalt-terapia, sua demanda é concentrada nas regiões de Brasília e Goiás, sem números expressivos para o Mato Grosso do Sul (Castelo Branco \& Carpes, 2017).

\section{Considerações Finais}

Esta investigação teve por objetivo descrever e analisar formas de disciplinarização da Gestaltterapia no Mato Grosso do Sul, entre 1980 e 1990. Ou seja, interessava-nos compreender como pupilos e professores estiveram envolvidos no processo de conformação da abordagem, na região. Particularmente, estimávamos identificar e analisar como tais atores se apropriaram e produziram conhecimentos e práticas vinculadas à Gestalt-terapia. Seus resultados indicam que tal processo ocorreu, em Campo Grande, a partir da constituição daquela que foi rememorada como a primeira turma de formação em Gestalt-terapia, do estado. A disciplinarização ora analisada deu-se durante um processo de expansão brasileira para o Oeste, fortemente capitaneada pelo governo civilmilitar. Isso se deu, tal qual as fontes sugerem, por implicações no ensino superior, no bojo de outras mudanças alardeadas como modernizadoras, no "milagre econômico".
As fontes orais e textuais sugerem, particularmente, que a disciplinarização da Gestalt-terapia fez parte de um processo mais geral, que ocorria no Brasil. Na segunda metade do século XX, houve a intensificação da circulação de teorias e objetos psicológicos vinculados a matrizes denominadas Humanistas e, entre elas, as Gestálticas. Nessa seara, a recepção de tais fenômenos ocorria pela importação e tradução de livros, mas, principalmente, pelo estabelecimento de cursos de formação. O curso aqui historicizado atendeu a um perfil de alunado misto, de acadêmicos de Psicologia e psicólogos. Em sua maioria era composto por mulheres, característica da Psicologia brasileira, à época, mas salientada no cenário campograndense. Essas pessoas eram, majoritariamente, egressas do curso de graduação em Psicologia, da FUCMT, primeiro da cidade e segundo do estado. Inclusive, foi a primeira a estabelecer a formação em Psicologia e, não, de Licenciatura Plena, na região. Todavia, não houve indícios do fomento da Gestalt-terapia, per se, durante a formação de nossos entrevistados.

A vinculação ao curso de formação em Gestaltterapia parece ter atendido a dois parâmetros estabelecidos por aqueles alunos. Primeiramente, parte daquelas pessoas se tornou interessada na Gestalt-terapia em decorrência de sua formação, na FUCMT, onde tiveram acesso a outras tradições denominadas Humanistas. Em segundo lugar, vale lembrar da dificuldade de acesso a livros e à formação complementar, na região, à época. Dessa forma, o curso poderia aliar o interesse em abordagens congêneres ao anseio de ampliar os horizontes de formação. As memórias orais e textuais analisadas indicam que o curso atendeu a tais parâmetros. A partir de uma configuração teórico-prática, aquelas pessoas tinham acesso a materiais que chegavam ao país, bem como aos que eram traduzidos e produzidos por gestaltistas brasileiros. Um exemplo disso era o próprio responsável pelo curso, Jorge Ponciano Ribeiro. A parcela vivencial, por sua vez, permitia o desenvolvimento da práxis psicoterápica e, também, oportunizava certa terapêutica aos participantes. Esses dois aspectos citados corroboram dados já historicizados sobre as características do processo de disciplinarização das abordagens ditas Humanistas, no país.

Por fim, acreditamos ser relevante indicar limitações em nosso estudo. Ele foi fortemente desenvolvido a partir de fontes orais que, inclusive, não compõem a totalidade de participantes do curso. Dessa forma, novos estudos poderiam se valer de outras fontes orais e, sobretudo, de fontes textuais. Não tivemos, por exemplo, acesso a anotações, livros ou separatas que circularam durante seu desenvolvimento. Outra possibilidade seria expandir nossas fontes para identificar e analisar produções científicas que desvelam características das práxis e conhecimentos intelectuais de gestalterapeutas, 
no estado. Entretanto, mesmo com tais limitações, acreditamos que o estudo clarificou aspectos ainda não narrados dessa história local. Tal feito estima dialogar com tendências atuais da História da Psicologia, quais sejam: compreender a relação global-local na história da Psicologia e como certos conhecimentos se tornaram locais.

\section{Referências}

Batur, S. (2011). Peripherialization and history of psychology: An example from Turkey. In: A. Marvakis; J. Motzkau; D. Painter; R. Ruto-Korir; G. Sullivan; S. Triliva; \& M. Wieser (Orgs.) - Doing Psychology Under New Conditions (pp. 131-138). Concord: Captus Press.

Cara, B. S. (2017). Memória da Psicologia em Campo Grande: uma história do curso de graduação em Psicologia da FUCMT (1980-1993). Dissertação (Mestrado em Psicologia), Programa de Pós-Graduação em Psicologia. Universidade Católico Dom Bosco: Campo Grande, MS. Brasil.

Castelo Branco, P. C., \& Carpes, C. O. (2017). Produção Gestáltica nas Bases de dados SCIELO e PEPSIC: Revisão Sistemática. Revista IGT na Rede, 14(6), 72-86. Recuperado de http://www. igt.psc.br/ojs

Castelo Branco, P. C., \& Cirino, S. D. (2017). Fenomenologia nas obras de Carl Rogers: apontamentos para o cenário brasileiro. Revista De Psicologia, 8(2), 44-52. Recuperado de http:// www.periodicos.ufc.br/psicologiaufc/article/ view/6719

Castelo Branco, P. C., \& Farias, H. B. (2020). Cientometria e bibliometria do campo da abordagem centrada na pessoa e Gestalt-terapia no Brasil: Análise das redes de autoria e produção. PHS: Phenomenology, Humanities and Science, 1, 31-43.

Castelo Branco, P. C., Farias, H. B., \& Leite, L. B. (2017). Influências humanistas na produção de conhecimento psicológico da Pontifícia Universidade Católica - Campinas. Revista do Nufen: Phenomenology and interdiciplinarity, 9, 1-15. Doi: http://dx.doi.org/10.26823/RevistadoNUFEN.vol09.n03artigo11

Danziger, K. (1985). Towards a conceptual framework for a critical history of psychology. In $\mathrm{H}$. Carpintero; \& J. M. Peiro (Orgs.), Psychology in its historical context: Essays in honour of J. Brožek (pp. 99-107). Valencia: Monografias de la Revista de História de la Psicologia.

Ferreira, M. M. (2000). História do tempo presente: Desafios. Cultura Vozes, 94, 111-124.
Gomes, W., Holanda, A., \& Gauer, G. (2004). História das abordagens humanistas em Psicologia no Brasil. In: M. Massimi (Org.), História da psicologia no Brasil do Século XX (pp. 105-129). São Paulo: EPU.

Gundlach, H. (2006). Psychology as science and as discipline: the case of Germany. Physis-Rivista Internazionale di Storia della Scienza, XLIII, 61-89.

Holanda, A. (2009). Gestalt-terapia e a abordagem gestáltica no Brasil: análise de mestrados e doutorados (1982-2008). Estudos e Pesquisas em Psicologia, 9(1), 98-123. Recuperado de http://www.revispsi.uerj.br/v9n1/artigos/pdf/ v9n1a09.pdf

Holanda, A. (2014). Fenomenologia e humanismo: reflexões necessárias. Curitiba: Juruá.

Holanda, A. F., \& Karwowski, S. L. (2004). Produção acadêmica em Gestalt-terapia no Brasil: Análise de mestrados e doutorados. Psicologia Ciência e profissão, 24, 60-71. DOI: http://dx.doi. org/10.1590/S1414-98932004000200008.

Jansz, J. (2009). Psychology and society: An overview. In. J. Jansz \& P. van Drunen (Orgs.), A social history of Psychology (pp. 12-44). Oxford: Blackwell Publishing. Originalmente publicada em 2004.

Koch, O. L. van (1975). O exercício da psicoterapia no Brasil. Revista Interamericana de Psicologia, 9(1), 111-123. Doi https://doi.org/10.30849/rip/ ijp.v9i1\%20\&\%202.727

Lei $n^{\circ} 4.119$, de 27 de agosto de 1962. (1962). Dispõe sôbre os cursos de formação em psicologia e regulamenta a profissão de psicólogo. Diário Oficial da União, Poder Executivo, Brasília, DF.

Mancebo, D. (1999). Formação em Psicologia: gênese e primeiros desenvolvimentos. In: A. M. Jacó-Vilela; F. Jabur; \& H. B. C. Rodrigues (Orgs.), Clio-Psyché: Histórias da Psicologia no Brasil (pp. 93-120). Rio de Janeiro: EdUERJ.

Moreira, V. (2009). A Gestalt-terapia e a Abordagem Centrada na Pessoa são enfoques fenomenológicos? Revista da Abordagem Gestáltica, 15(1), 3-12. Recuperado de http://pepsic.bvsalud.org/ pdf/rag/v15n1/v15n1a02.pdf

Moro, N. (2012). Uma cidade (In)civilizada: elite, povo comum e viver urbano em Campo Grande (décadas 1960-1970). Clio: Revista de Pesquisa Histórica, 30, 1-27. Recuperado de https:// periodicos.ufpe.br/revistas/revistaclio/article/ view/24353 
Mota, A. M. D. G. F., Cara, B. S., \& Miranda, R. L. (2018). História da Psicologia, por quê? Estudos e Pesquisa em Psicologia, Dossiê História Social da Psicologia, 18(4), 1049-1067. Recuperado de https://www.e-publicacoes.uerj.br/index.php/ revispsi/article/view/42222

Motta, R. P. S. (2014). As universidades e o regime militar: cultura política brasileira e modernização autoritária. Rio de Janeiro: Zahar Editora.

Mulheres Invadem a FUCMT. (1975, 12 janeiro). Diário da Serra. Campo Grande, MS.

Müller-Granzotto, M. J., \& Müller-Granzotto, R. L. (2007). Fenomenologia e Gestlt-terapia. São Paulo: Summus.

Perls, F. S. (1977a). Gestalt-terapia explicada. São Paulo: Summus. Obra originalmente publicada em 1975.

Perls, F. S. (1977b). Isto é Gestalt. São Paulo: Summus. Obra originalmente publicada em 1969.

Perls, F. S., Hefferline, R., \& Goodman, P. (1997). Gestalt-terapia. São Paulo: Summus. Obra originalmente publicada em 1951.

Ribeiro, J. P. (1985). Gestalt-terapia: refazendo um caminho. São Paulo: Summus.

Rosemberg, F. (1984). Afinal, por que somos tantas psicólogas? Psicologia: Ciência e Profissão, 4, 6-12. DOI: 10.1590/S1413-294X1998000100011

Russo, J. A. (2005). O movimento psicanalítico brasileiro. In: A. M. Jacó-Vilela; A. A. L. Ferreira \& F. T. Portugal (Orgs.), História da Psicologia: $R u-$ mos e percursos (pp. 413-424). Rio de Janeiro: Nau Editora.

Rutherford, A. (2012). O feminismo precisa da Psicologia? Reconstruindo a história de uma relação. In: A. M. Jacó-Vilela, \& F. T. Portugal (Orgs.), Clyo-Psyché: Gênero, psicologia, história (pp. 23 - 41). Rio de Janeiro: Nau Editora.
Sampaio, H. (2000). O ensino superior no Brasil: o setor privado. São Paulo: FAPESP/ Hucitec.

Spiegelberg, H. (1972). Phenomenology in psychology and psychiatry. Evanston: Northwester University Press.

Suassuna, D. M. C., \& Holanda, A. F. (2008). História da Gestalt Terapia no Brasil contada por seus "primeiros autores": um estudo historiográfico no eixo São Paulo- Brasília. Dissertação (Mestrado em Psicologia), Universidade Católica de Goiás. Goiania- GO.

Tellegen, T. (1984). Gestalt e grupos: uma perspectiva sistêmica. São Paulo: Summus.

Lívia Elena Cunha Laura: acadêmica do curso de Psicologia da Universidade Católica Dom Bosco.

Ana Camila Marcelo: acadêmica do Programa Lato Sensu em Terapia Analítico Comportamental da Universidade Católica Dom Bosco.

Elena dos Santos Arsamenia: acadêmica do curso de Psicologia da Universidade Católica Dom Bosco.

Giovanna Figueiredo Barzotto: Acadêmica do curso de Psicologia da Universidade Católica Dom Bosco.

Ana Maria Del Grossi Ferreira Mota: doutoranda do Programa de Pós-Graduação Mestrado e Doutorado da Universidade Católica Dom Bosco; bolsista de Doutorado CAPES.

Rodrigo Lopes Miranda: professor titular do Programa de Pós-Graduação em Psicologia da Universidade Católica Dom Bosco (UCDB); bolsista de Produtividade em Pesquisa CNPq.

Recebido em 20.11.2020

Primeira decisão editorial em 18.02.2021

Aceito em 11.03.2021

\footnotetext{
${ }^{1}$ A pesquisa que subjaz a este artigo foi autorizada pelo Comitê de Ética em Pesquisa (CEP), da Instituição em que foi realizada, tendo sido aprovada pelo mesmo, conforme CAAE 00832818.7.0000.5162. Todos(as) os(as) entrevistados(as) assinaram Termo de Consentimento Livre e Esclarecido (TCLE), em que constava o seu anonimato. Assim, eles(as) serão identificados, neste texto, por Entrevistado(a) 1, Entrevistado(a)
} 2 e, assim, sucessivamente. 